\title{
POR UMA EDUCAÇÃO VISUAL A PARTIR DOS OBJETOS: DEBATES SOBRE O MÉTODO DUPLO-MUSEU APLICADO ÀS EXPOSIÇÕES
}

\author{
Ana Carolina Gelmini de Faria*
}

\section{RESUMO}

Na primeira metade do século XX agentes brasileiros que atuavam no campo dos museus comprometiam-se com o aprimoramento da função social dessas instituições e, nessa perspectiva, a educação em museus protagonizou os debates. Publicações do período revelam estratégias de uma educação para o "povo" por meio dos objetos. O trabalho propõe analisar o Método DuploMuseu, que tinha por objetivo de estimular a percepção visual dos visitantes e intensificar o valor pedagógico dos objetos nas exposições.

Palavras-chave: campo dos museus, história dos museus, educação em museus, educação visual, Método Duplo-Museu.

* Universidade Federal do Rio Grande do Sul (UFRGS), Porto Alegre/RS, Brasil. 


\title{
POR UNA EDUCACIÓN VISUAL A PARTIR DE LOS OBJETOS: DEBATE SOBRE EL MÉTODO DOBLE MUSEO APLICADO A LAS EXPOSICIONES
}

\section{RESUMEN}

En la primera mitad del siglo XX, agentes brasileños que actuaban en el campo de los museos se comprometían con el perfeccionamiento de la función social de estas instituciones y, en esta perspectiva, la educación en los museos protagonizó los debates. Publicaciones del período revelan estrategias de una educación para las personas a través de los objetos. El trabajo propone analizar el Método Doble Museo, que tenía por objetivo estimular la percepción visual de los visitantes e intensificar el valor pedagógico de los objetos en las exposiciones.

Palabras clave: campo de los museos, historia de los museos, educación en los museos, educación visual, Método Doble Museo.

\section{FOR A VISUAL EDUCATION FROM OBJECTS: DEBATES ON THE DOUBLE-MUSEUM METHOD APPLIED TO THE EXHIBITIONS}

\begin{abstract}
In the first half of the twentieth century Brazilian agents working in the field of museums were committed to improving the social function of these institutions and, in this perspective, education in museums led the debates. Publications of the period reveal strategies of an education for the people through objects. This paper proposes to analyze the Double-Museum Method, which aimed to stimulate the visual perception of the visitors and to intensify the pedagogical value of the objects in the exhibitions.
\end{abstract}

Keywords: field of museums, history of museums, museum education, visual education, Double-Museum Method.

\section{POUR UNE ÉDUCATION VISUELLE À PARTIR DES OBJETS: DÉBATS SUR LA MÉTHODE DOUBLE-MUSÉE APPLIQUÉ AUX EXPOSITIONS}

\section{RÉSUMÉ}

Au cours de la première moitié du XXe siècle, les agents brésiliens travaillant dans le champ des musées se sont engagés à améliorer la fonction sociale de ces institutions et, à partir de cette perspective, l'éducation muséale a joué un rôle actif sur les débats. Les publications de l'époque révèlent des stratégies d'éducation du peuple à travers les objets. Le travail propose d'analyser la Méthode Double-Musée, qui visait à stimuler la perception visuelle des visiteurs et à intensifier la valeur pédagogique d'objets aux expositions.

Mots-clés: champ des musées, histoire des musées, éducation muséale, éducation visuelle, Méthode Double-Musée. 


\section{EDUCAÇÃO EM MUSEUS: UM INTENSO DEBATE NA PRIMEIRA METADE DO SÉCULO XX}

No Brasil, quando se trata de educação em museus, ainda há dificuldade em traçar uma trajetória histórica desse processo nesse campo. Inúmeras ações educativas são realizadas por espaços de caráter museal, mas essa é uma atividade que carece de análises, reflexões e avaliações contínuas. Quando se trata de interpretar uma história da educação em museus os desafios se tornam ainda mais intensos, pois há hiatos de fontes e poucas produções investigativas com esse viés, embora sejam abundantes as evidências de sujeitos e projetos sobre o tema, mas estão em sua maioria dissociados e distribuídos sem articulação em diferentes espaços de guarda documental.

O tema educação em museus no Brasil é revelador. As pesquisas realizadas sobre os debates, projetos e ações promovidos entre a primeira metade e meados do século XX, na perspectiva da História da Educação e da História dos Museus (CHAGAS, RODRIGUES, 2019; FARIA, 2017; GIL, POSSAMAI, 2014; KNAUS, 2011), se deparam com um cenário instigante, no qual é possível afirmar: 1) A educação em museus se tornou uma função que legitimou o campo dos museus no período apontado; 2) As discussões sobre educação em museus estavam alinhadas aos debates internacionais do campo dos museus e da educação; 3) A educação em museus potencializou uma intensa produção sobre o tema, de caráter teórico-metodológico, que influenciou a forma dos museus se relacionarem com seus públicos.

O conteúdo apresentado nesse trabalho é derivado da pesquisa de doutorado da autora e concentra vestígios dos debates obtidos por meio de uma vasta pesquisa documental de fontes produzidas por agentes que atuaram no campo dos museus na primeira metade e meados do século XX. Seu foco dar-seá no terceiro apontamento, apresentando um método estudado pelos profissionais da época para potencializar a educação visual nos museus, denominado Método Duplo-Museu. A análise desse método aproxima o estudo dos museus da História da Educação, especialmente a produzida fora do contexto 
escolar.

\section{A EDUCAÇÃO EM MUSEUS: UMA FUNÇÃO QUE LEGITIMOU O CAMPO DOS MUSEUS NO SÉCULO XX}

A primeira metade do século XX foi intensa, marcada pelas duas guerras mundiais. O tema educação em museus ganhou atenção explícita nesse período, especialmente após a Segunda Guerra Mundial. A motivação pode ser atribuída à criação da Organização das Nações Unidas para a Educação, a Ciência e a Cultura (Unesco), em 1945, e do Conselho Internacional de Museus (ICOM), no ano seguinte, elementos decisivos para o impulso da discussão ao promoverem eventos que reuniram uma diversidade de experiências e aproximaram agentes com diferentes conhecimentos e vivências para debater sobre educação em museus.

O ICOM, fundado em 1946, tem por objetivo promover uma cooperação internacional entre os museus, por meio da organização de intercâmbios, congressos e publicações, e impulsionou a educação em museus como um dos temas centrais de seu projeto de consolidação, refletindo e revisando as competências dos museus ${ }^{1}$. A Unesco, órgão com o qual o ICOM mantém relações formais, deu início, na década de 1950, a diversos eventos internacionais que tiveram como assunto central o tema educação em museus, a exemplo do Seminário Regional da Unesco sobre A Função Educativa dos Museus, realizado no Rio de Janeiro/Brasil em 1958².

\footnotetext{
${ }^{1}$ Esse movimento foi consolidado no Conselho Internacional de Museus (ICOM) com a fundação em 1968 do Committee for Education and Cultural Action (CECA) [Comitê Internacional de Educação e Ação Cultural]. Sua primeira conferência teve como tema "O papel dos museus na educação e ação cultural”, realizada em Moscou e, de acordo com seu site, desde então reúne interessados em educação e ação cultural aplicada ao patrimônio. Informações sobre o CECA. Disponível em: http://network.icom.museum/ceca/. Acesso em: 16 nov. 2019.

2 Para informações sobre o Seminário Regional da Unesco realizado em 1958 é possível consultar o documento final do evento. Disponível em: https://unesdoc.unesco.org/ark:/48223/pfoooo133845. Acesso em: 16 nov. 2019.
} 
Interessante observar que em um período onde a dinamicidade ganhava espaço, a exemplo do cinema e da televisão, debates sobre a educação em museus contribuíam para não só legitimar os museus enquanto espaços educativos contemporâneos, mas também para articulá-los a novos recursos que consolidassem sua característica de protagonizar a educação pelo visual. Segundo Sigrid Porto de Barros ([1952] 1964, p. 228), conservadora de museus do Museu Histórico Nacional: "O esplêndido isolamento das grandes coleções, preservadas em vetustas galerias, terá que dar lugar a coleções vivas, utilizadas culturalmente, de forma dinâmica, que agradem o público, mas o eduquem sutilmente e ofereçam uma sadia fonte de distrações estimulantes do espírito". Um dos exemplos dessa articulação foi o uso do cinema educativo enquanto estratégia audiovisual nas exposições. A conservadora de museus Dulce Ludolf ([1952] 1964), também funcionária do Museu Histórico Nacional, sugeria a utilização dos recursos mais contemporâneos nessa operação:

O cinema, a maior distração popular do nosso século, atraindo um público de milhares de expectadores, oferece uma incomparável oportunidade à difusão das ideias e dos conhecimentos em geral. Muitos programas podem ser realizados mostrando coisas curiosas, tão comuns nos museus, fáceis de despertar o interesse do público (LUDOLF, (1964 [1952], p. 194).

A proposta de associar recursos como o cinema, a televisão e o rádio aos museus se reforçava pelo argumento de que esses eram capazes de fomentar a função social dos museus pelo contato visual com o patrimônio. Esse tema será explorado adiante. Mas cabe ressaltar ponderações como a de Edgar Süssekind de Mendonça (1946), educador vinculado ao Museu Nacional e um dos signatários do Manifesto dos Pioneiros da Educação Nova (1932), que defendia que os museus precisavam aperfeiçoar os recursos didáticos de apresentação dos registros materiais. Barbosa (2015) identifica que o educador "[...] chega a dizer que a função dos museus é preservar, investigar e educar, sendo esta última a função social mais importante dos museus" (p. 294, grifo meu). 
Anísio Teixeira, educador e também signatário do Manifesto dos Pioneiros da Educação Nova, em entrevista cedida em 1956 para o Jornal Correio da Manhã destacou que os museus eram sim espaços de educação e que essa função o legitimava por ter a especificidade de estimular a compreensão da vida e do humano através do duplo sentido do ver - os museus seriam capazes de explorar o sentido da visão e, através dos registros materiais, projetar interpretações do passado, interesses do presente e perspectivas de futuro (TEIXEIRA apud MAURÍCIO, 1956). De acordo com o educador:

\begin{abstract}
Antes da escola, o museu
Lembra o entrevistado [Anísio Teixeira] os que pensam que só o lar e a escola são instituições educativas e que os museus seriam somente instituições de cultura... Mas a educação, pondera, é o resultado de nossas transações com o "mundo", e o "mundo" e as "pessoas" são coisas complexíssimas, altamente elaboradas, e o resultado de longo, difícil e contínuo processo de civilização; E todo esse processo é que os museus e livros buscariam documentar - daí serem os museus e bibliotecas as instituições da educação (TEIXEIRA apud MAURÍCIO, 1956, [s.n.t.]).
\end{abstract}

O papel social dos museus, pelo viés da educação, passou a ser considerado. Vestígios dos primeiros contornos dos debates sobre educação em museus e seus aspectos sociais culminaram, na segunda metade do século XX, no advento da Museologia Social.

Cabe enfatizar que a função educativa dos museus foi associada pelos agentes do campo à educação visual. Bertha Lutz, funcionária do Museu Nacional, denominou de educação visual no museu as técnicas voltadas para montagens expográficas no domínio da instrução pública, valorizando o museu como instrumento cultural. A pesquisadora defendia que o aprendizado pelo sentido visual nos museus tornava, em sua opinião, o acesso ao conhecimento democrático e, consequentemente, os museus como espaços de utilidade pública (LUTZ, [1932] 2008).

Pesavento (2008) observa que o visível possui especificidades, 
especialmente quando comparamos com o recurso textual. A pesquisadora aponta cinco particularidades passíveis de contemplar o processo de visualização de toda materialidade: a probabilidade de exibir o todo de uma só vez, elementos, cena e personagens; a capacidade de fixar uma representação visual, fortalecida pela sua capacidade de fascínio e capacidade evocativa; a possibilidade de proporcionar uma comunicação imediata pela sedução e encantamento, despertando a atenção pelo olhar; a indicação de seus limites físicos, dificultando que a visualização do conteúdo seja imaginada de outras formas; e a indução a pensar no abismo entre o que se vê e o mundo daquilo que é dito, conferindo prioridade ao ver. Esses indicativos estavam presentes nas discussões sobre educação em museus, especialmente no que tange a proposta do Método DuploMuseu.

\section{DISCUSSÕES SOBRE EDUCAÇÃO EM MUSEUS: ALINHAMENTO DOS AGENTES DO BRASIL COM OS DEBATES INTERNACIONAIS DO CAMPO}

Embora na primeira metade do século XX não houvesse $\mathrm{o}$ acesso instantâneo à informação por meio das tecnologias da informação e comunicação como vivenciamos cotidianamente, indícios demonstram que as publicações sobre museus no Brasil tratavam dos temas mais contemporâneos do campo, articulados diretamente com a produção internacional. Nessa perspectiva, os estudos sobre educação em museus, conjugados, permitem um panorama das questões e soluções pensadas no período pelos profissionais que atuavam nos museus. Três movimentos podem exemplificar a afirmativa: a) o acesso às publicações internacionais; b) a ida aos museus internacionais e, consequentemente, o contato com profissionais e suas produções; c) a realização de eventos internacionais promovendo o intercâmbio de informações.

Um documento (sem data de sua elaboração) que evidencia o acesso às publicações internacionais é o escrito de Nair Moraes de Carvalho, conservadora 
de museus do Museu Histórico Nacional, localizado no Núcleo de Memória da Museologia no Brasil da Universidade Federal do Estado do Rio de Janeiro (Nummus/Unirio). Aparentando ser um esboço de uma versão final do documento, mas com acréscimos e rasuras em letra cursiva, as cinco laudas datilografadas concentram uma análise sobre o Método do Duplo-Museu, que será abordado adiante. Cabe aqui salientar que no início do texto a autora menciona um trabalho publicado no Les Cahiers de la République des Léttres des Sciences et des Arts de Paris como o melhor estudo apresentado até então no campo dos museus.

A coletânea Les Cahiers de la République des Léttres des Sciences et des Arts de Paris foi lançada em 1926. Sua periodicidade se alterou ao longo das impressões e os temas abordados eram dos mais variados 3 . Impresso em 1931, o número 13 da coletânea foi intitulado Musées, composto por contribuições de autores de diferentes países. A proposta dos organizadores do Les Cahiers era estimular que os museus assumissem seu papel de proteger o passado, como instituições educacionais e científicas, a partir do debate internacional sobre problemas técnicos essenciais próprios dessas instituições (BERTHELOT; HILAIRE; BRUNON-GUARDIA, 1931).

Os temas abordados pelos colaboradores, embora tivessem recortes dos mais variados, como museus de arte, históricos, etnográficos da Europa e da América do Norte, por exemplo, tratavam de tópicos convergentes, tais como missão de um museu, organização administrativa, conservação de bens culturais, documentação, iluminação, montagem de exposições, recursos no espaço e circulação de visitantes, publicidade. Esses temas contribuíam para o debate de estratégias de educação visual, como o Método Duplo-Museu.

Angyone Costa, professor da disciplina Arqueologia aplicada ao Brasil do Curso de Museus vinculado ao Museu Histórico Nacional - autorizado em 1932,

\footnotetext{
3 Informações sobre a coletânea Les Cahiers de la République des Léttres des Sciences et des Arts de Paris disponíveis em: http://catalogue.bnf.fr/ark:/12148/cb32735486b. Acesso em: 16 nov. 2019.
} 
que formava conservadores de museus, citou em entrevista concedida em 1934 sobre a publicação internacional:

Ao dr. Gustavo Barroso devemos a organização magnífica por ele dada à cadeira complexa que lhe coube lecionar: Técnica de Museus, matéria inteiramente nova no Brasil. Senhor de uma larga cultura, o ilustre escritor não teve dificuldades em redigir seu admirável programa agora em completa evidência, diante da publicação do livro "Musées", primeiro da coletânea "Les Cahiers de la République des Léttres des Sciences et des Arts de Paris", onde as maiores autoridades na matéria demonstram que o ponto de vista escolhido aqui é o melhor (COSTA, 19344 apud RIBEIRO, 2014, p. 83).

Observa-se, portanto, que o material didático da disciplina Técnica de Museus, intitulado Introdução à Técnica de Museus, escrito pelo diretor do Museu Histórico Nacional da época, Gustavo Barroso, tenha tido o volume Musées como uma referência, hipótese comprovada ao analisar as fontes bibliográficas da Parte Geral do livro (BARROSO, 1951). Ressalta-se que um dos possíveis acessos de Gustavo Barroso à publicação foi em sua passagem pela França entre agosto e outubro de 1931, como correspondente e editor da revista Fon-Fon (RIBEIRO, 2014). O Método Duplo-Museu é um dos temas tratados no livro Introdução à técnica de museus (BARROSO, 1951).

Outra fonte que aparece na lista das referências do livro Introdução à técnica de museus (BARROSO, 1951) é a publicação Museographie. Intitulado Muséographie: architecture et aménagement dês musées d'art, em dois volumes, concentra os trabalhos de uma conferência de especialistas sobre museografia que ocorreu em Madrid, na Espanha, no período de 28 de outubro a 4 de novembro de 1934 (CRUZ, 2008).

Esta obra totaliza 526 páginas, sendo o primeiro volume dedicado a questões arquitetônicas - luz, espaço, montagem de exposição - e o segundo, a

4 COSTA, Angyone. A expansão da cultura brasileira. Diário de Notícias, Rio de Janeiro, 22 abr. 1934, p. 1; 8. 
gestão de acervos. Considerado uma obra rara, o Nummus/Unirio possui o segundo volume desta publicação, o que permite observar os principais debates do período, dos quais destacam-se material para exposição dos acervos; numeração e etiquetagem de coleções; técnicas e estética (OFFICE INTERNATIONAL DES MUSÉES, 1935), ou seja, é uma obra que marca o direcionamento da construção de estratégias de exibição de acervo e visitação.

As duas obras citadas evidenciam que os profissionais brasileiros tinham acesso aos debates internacionais mais contemporâneos do período e que, na situação exemplificada, tornaram-se fontes de pesquisa para a elaboração de material didático do Curso de Museus, formação que diplomou diversos conservadores de museus para atuarem nos museus brasileiros. Muitos profissionais do campo, além do contato com publicações internacionais por meio das aulas do Curso de Museus ou do contato com livros nacionais especializados, tiveram a oportunidade de se participarem dos debates sobre educação em museus por meio de suas experiências pessoais no exterior.

Um dos roteiros mais visitado para estudos de museus na primeira metade do século XX foi os Estados Unidos da América. Muitos dos profissionais de museus que foram obtiveram bolsas de estudo e, em seu retorno, elaboraram relatórios e livros, documentos que hoje permitem analisar o que era destacado por eles como novas tendências em relação à educação em museus.

Um exemplo de registros de viagem encontrado foi o da profissional de museus Bertha Lutz, funcionária do Museu Nacional, onde trabalhou por mais de 40 anos. No relatório, inicialmente intitulado O papel educativo dos museus norte-americanos, ela registrou sua ida aos Estados Unidos, em 1932, com foco no processo socioeducativo promovido pelos museus norte-americanos.

No decorrer da visita patrocinada Bertha Lutz focou sua análise nos departamentos e serviços educativos. Sobre a relação dos museus norteamericanos com o público analisou: "[...] procuram interessar todas as camadas de seres humanos, desde a criança até o velho, desde o aprendiz até $o$ pesquisador" (LUTZ, [1932] 2008, p. 67). A educação visual foi o que mais lhe 
chamou a atenção. Para ela, as técnicas museográficas eram elaboradas para o estímulo da principal característica - e vantagem - do papel educativo dos museus: a educação visual. A fim de potencializar as atividades educativas centradas nessa qualidade os profissionais dos museus norte-americanos estavam, segundo a autora, dotando as técnicas de controle científico. Em sua percepção esse movimento era radical e transgressor. Em um de seus registros, destacou:

O conceito do museu está em plena evolução. A evolução se opera no sentido da educação do povo e da democratização cultural. O museu reconhece hoje o seu duplo objetivo de conservador e de ampliador dos conhecimentos humanos e de órgão de divulgação popular. Vários fatores têm influído na evolução dos museus; alguns econômicos, outros científicos, outros sociais. Por um lado, é mais fácil obter subvenções para os museus que desenvolvem programas de educação do povo; por outro, acentua-se a tendência de exigir a retribuição, sob a forma de serviços culturais e populares, dos subsídios pecuniários públicos gastos na manutenção dos museus. [...] O elemento subjetivo (o visitante) vem sendo estudado pela primeira vez. [...]. As doutrinas filosóficas e os fatores sociais, econômicos e científicos, supracitados, estão produzindo modificações radicais da técnica museológica, abrindo ao museu vastas perspectivas de utilidade pública e oportunidades preciosas de concorrer eficazmente para a disseminação da cultura popular. (LUTZ, [1932] 2008, p. 40-41)

Outro profissional de museus que teve a oportunidade de conhecer o trabalho das instituições norte-americanas por meio de bolsa de estudos, em 1943, foi José Antonio do Prado Valladares, na época diretor do Museu do Estado da Bahia. As impressões de Ceravolo (2012) sobre o relato de Valladares apontam para um esforço dos funcionários dos museus norte-americanos em conquistar o visitante. Valladares (1946) endossava as impressões dos profissionais brasileiros, que atuavam no campo dos museus, sobre a experiência das instituições estrangeiras: o visitante ganhava protagonismo frente à ostentação das coleções preservadas.

Valladares defendia que a difusão cultural era o principal objetivo dos 
museus. Ceravolo (2012) identifica que Valladares (1946) apresentava para o leitor, a partir dos exemplos que vivenciou, a possibilidade de um museu como prestador de serviços para a educação. Essas instituições passaram a ter "[...] um "esforço consciente e orientado" para atrair, entreter e prover com informações seus visitantes, que assim, adquiriam mais conhecimentos" (CERAVOLO, 2012, p. 771). O profissional de museus define, em seu registro da experiência da bolsa de estudos, o que entendia por museus a serviço da educação para o "povo" 5 :

\begin{abstract}
Quando se fala em museu a serviço da educação do povo, é importante reparar que não se trata, apenas, do proveito que alguém poderá auferir da contemplação, embora entusiasmada, de obras de arte, ou da inspeção, embora curiosa, de objetos com significação histórica ou valor científico; na realidade, trata-se de esforço consciente e orientado no sentido de atrair o público e, uma vez com o público dentro das galerias, proporcionar entretenimentos que o prendam, ao lado das informações que se vão acrescentar à soma de conhecimentos com que transpôs as portas da instituição (VALLADARES, 1946, p. 3).
\end{abstract}

Observa-se que, ao atribuir à educação em museus a qualidade de educar o "povo", o autor realiza uma operação que confere um papel de responsabilidade à educação visual. Ele reforça que a proposta não é somente proporcionar contemplação e curiosidade sobre o visível, mas de apresentar os objetos ao público como fontes de informação. Essas estratégias tinham uma finalidade: a de atrair o homem médio para os museus e promover o aprendizado pela visualidade:

A fim de conseguir tal objetivo, o museu não se pode limitar à apresentação técnica das coleções que possui. Terá, em primeiro lugar, de saber atrair o visitante; depois, de tornar os momentos de permanência nas galerias, momentos agradáveis; finalmente, deverá

\footnotetext{
$5 \mathrm{O}$ conceito de povo era associado à ideia de público de forma recorrente, porém com conotações características do momento vivido. De acordo com Mendes (2015, p. 8) “[...] O 'povo', aqueles que não faziam parte da 'elite". Velloso (1987, p. 46) enfatiza que o mesmo povo era simultaneamente configurado como inconsciente, analfabeto e deseducado: "É, portanto, através da 'educação popular' que se busca assegurar a positividade dessa categoria social, impedindo que se descambe para o caos, a desordem, a negação".
} 
cuidar de que o visitante deixe suas portas, tendo aprendido alguma coisa de novo e - o que é da maior importância - com um desejo forte de relatar a experiência àqueles com quem priva. Somente por esses meios se poderá pretender que o homem médio seja atingido: quer apresentando motivos para que ele vá ao museu, quer levando pessoas de seu conhecimento a falar-lhe das coisas interessantes que viu e aprendeu (VALLADARES, 1946, p. 9).

Outro registro encontrado foi de Nair Moraes de Carvalho, conservadora de museus do Museu Histórico Nacional. Em 1945 preconizou uma viagem técnica aos museus dos EUA no período de 19 de novembro de 1945 a 21 de fevereiro de 1946, tendo por objetivo conhecer o funcionamento das instituições americanas, em especial sobre a gestão de acervos, enfatizando a organização, catalogação, exposições e práticas educativas (CARVALHO, 1946).

Um dos destaques da profissional sobre sua experiência foi em relação a programações e materiais disponibilizados para o visitante: os museus norteamericanos ofereciam uma ampla relação de aprendizagem e lazer sendo, em suas palavras, espaços de recreio, de estudo e mesmo de prazer, cumprindo seu papel cultural na vida moderna. Entre todos os museus visitados, o que mais impressionou a conservadora de museus em relação às ações para o público foi o Metropolitam Museum of Art, em especial, pelo Junior Museum, instituição vinculada à primeira citada. O Junior Museum, considerado pela autora único do gênero, era um centro de atividades para o público infantil, exercendo o papel de colaborador para a aprendizagem deste público a partir de seus acervos (CARVALHO, 1946).

É possível identificar, tanto na análise de Lutz ([1932] 2008), como na de Valladares (1946) e Carvalho (1946), que as funções do museu de preservar e investigar associam-se ao ato de promover o patrimônio cultural por meio da educação. Esse era um dos principais temas dos eventos que ocorreram em meados do século XX, promovidos pela Unesco com parceria do ICOM.

No ano de 1950 a educação em museus foi um dos pontos abordados na segunda conferência bienal do ICOM, como mencionado, fundado em 1946. Já 
em 1952 passou a ser o tema central do Seminário Internacional da Unesco, intitulado Sobre o papel dos museus na Educação, realizado em Nova York, EUA. No segundo Seminário Internacional da Unesco, realizado em 1954 em Atenas, Grécia, o tema central se manteve sob o mesmo título, com intenção de reforçar a aproximação entre museus e educação (TRIGUEIROS, 1958). Quatro anos depois, aprofundando os debates realizados, ocorreu o primeiro Seminário Regional da Unesco intitulado a Função Educativa dos Museus, tendo como cidade sede o Rio de Janeiro, Brasil.

O Seminário Regional Latino-Americano da Unesco, ocorrido no período de 7 a 30 de setembro de 1958 com sede no Museu de Arte Moderna do Rio de Janeiro, teve por proposta debater a função que estes ambientes deveriam cumprir como meio educativo para a população (KNAUSS, 2001). Nessa perspectiva foram promovidos relatos, conferências, mesas-redondas, visitas técnicas sobre recursos didáticos e técnicos dos museus (TORAL, 1995). O documento final produzido neste seminário definiu algumas características da educação em museus e apontou necessidades para sua execução. Segundo o registro do encontro, o museu é um espaço em benefício à educação, pois seu principal veículo de comunicação, as exposições, tem por si só valor didático (RIVIÈRE, 1958).

Sendo 1958 um ano em que o Brasil, motivado pela organização e realização do evento buscou reforçar os vínculos entre museus e escolas, não é de se estranhar que uma produção intensa sobre educação em museus fosse publicada neste referido ano. Estes trabalhos demonstram uma sintonia dos profissionais com os debates internacionais da área, tornando-se marcos do pensamento museológico brasileiro. Entre as publicações destacam-se os livros: Recursos educativos dos museus brasileiros, de Guy José Paulo de Hollanda; Museu e educação, de Florisvaldo dos Santos Trigueiros; e Museu ideal, de Regina Monteiro Real. Nesse período o Método Duplo-Museu era estabelecido como uma estratégia para a educação visual, solução que tornava os museus espaços singulares para um projeto de nação assegurado pela instrução pública. 


\section{O MÉTODO DUPLO-MUSEU}

Nas publicações dos profissionais de museus da primeira metade e meados do século XX um dos principais assuntos para se alcançar a educação visual era a arrumação do museu, atividade que envolve a primeira tomada de decisão: o que mostrar ao público? Quatro documentos distintos (CARVALHO, 19[--]; BARROSO, 1951; LUTZ, [1932] 2008; VALLADARES, 1946), produzidos entre as décadas de 1930 e 1940, serão objetos de análise das propostas de novas técnicas de arrumação das salas expositivas e apresentação dos objetos, tendo por ênfase o Método do Duplo-Museu. Esse era um método sugerido para concentrar o impacto visual sobre o visível e para estabelecer estratégias de narrativa para o público.

Um dos registros, de 1932, consta no relatório de visita técnica aos museus norte-americanos de Bertha Lutz ([1932] 2008). Ao problematizar a fundamentação da dupla função dos museus, a naturalista reflete:

Assim como a sua origem, é dupla a sua função. Já em 1864, Gray a define, quando diz que ao museu compete: "Primeiro, difundir a instrução e contribuir para o recreio intelectual da massa do povo; segundo, proporcionar ao pesquisador científico o ensejo de examinar detidamente todos os espécimes que constituem as coleções do Museu". Vejamos agora a prática. Corresponderá ela verdadeiramente ao ideal almejado nas palavras de Ruthven quando proclama o "museum of living thougth, a center of learning - a principal agency for the enlightment os the people" ["Um museu de pensamento vivo, um centro de aprendizagem - uma agência fundamental para ilustração do povo"]. Na realidade, até as últimas décadas, os museus tinham descurado um tanto o aspecto popular de sua função educativa, dedicando-se quase que exclusivamente ao papel de elemento material subsidiário à disposição do pesquisador. As coleções eram organizadas de modo a facilitar as investigações científicas, não obstante a aridez desta modalidade de exposição. Por grande favor admitia-se o público a percorrer as salas e ler os rótulos anexados aos espécimes, muitas vezes reduzidos, nos museus de ciência, à nomenclatura científica incompreensível para o leigo e, nos museus de arte, ao nome do autor da obra, sua data de nascimento e morte.

Agora não é mais assim. O museu contemporâneo está começando a adquirir consciência de seu papel de esclarecedor da massa do povo e a 
envidar todos os esforços nesse sentido (LUTZ, [1932] 2008, p. 31).

Observa-se que a proposta do Método do Duplo-Museu, apresentado por Lutz ([1932] 2008), segmenta o público do museu em dois eixos: o "povo" e o pesquisador científico ou, como Trigueiros (1958) classificou mais tarde, os curiosos e os estudiosos/ pesquisadores. O método seria uma proposta para viabilizar a educação visual, sobretudo do "povo", uma vez que se centrava na seleção de acervos apresentados e na ampliação de espaço para circulação. A dupla função apresentada por Lutz ([1932] 2008) tem, em um documento avulso com autoria de Nair de Moraes Carvalho, uma denominação para seu motivo gerador: $\mathrm{o}$ atravancamento.

O título escolhido para sua análise foi objetivo: O Método do DuploMuseu. A conservadora de museus iniciou o texto destacando que o acúmulo de coleções e, consequentemente, a falta de espaço, tornou-se um problema nos museus que exigia dos técnicos uma solução radical. O atravancamento preocupava os diretores e conservadores, pois causava confusão e mau efeito nas exposições (CARVALHO, 19[--]).

O Método do Duplo-Museu, segundo a autora, tinha sido proposto há meio século por conservadores estrangeiros e explica que o método fundamentase na divisão, em duas partes, do material de um museu: “[...] a parte que pela sua beleza, riqueza, fama, etc., seduz a toda gente; a parte que, sem esse brilho, é preciosa aos pesquisadores e estudiosos" (Idem, 19[--], p. 2).

Essa medida era experimentada pelos técnicos de museus a fim de reduzir à exposição pública, prioritariamente, as obras do primeiro conjunto. Para endossar a ampla utilização do método pelas instituições Nair de Moraes Carvalho citou 14 profissionais de museus, entre conservadores, diretores, arquitetos, e destacou suas opiniões sobre o método, nas quais é possível reproduzir algumas das considerações: 
[...] Schmidt-Degener, Diretor Geral do Rijksmuseum de Amsterdam, acha necessário não cansar o público, dando-lhe somente a ver o que for necessário e guardando a demasia para os especialistas.

[...] O Visconde de Abarnon, Presidente da Real Comissão dos Museus Nacionais da Grã-Bretanha, julga apoiado por unanimidade pela referida comissão, que o método é imprescindível à valorização do que o público deve ver com proveito e a facilitação do trabalho dos que desejam somente aprofundar em estudos.

[...] Marcel Nicolle, adido honorário do Museu do Louvre, mostra que esse método é a mais racional concepção moderna em museologia.

[...] O professor Ricardo Graul, ex Diretor dos Museus de Arte de Leipzing, pensa da mesma maneira nestas palavras: "As produções medíocres podem ter mérito aos olhos do historiador, do colecionador, do técnico, sendo indispensável o seu estudo. Mas, para emocionar o grande público, missão essencial do museu, para incitar-lhe o vago sentimento de beleza, decerto só o que se poder ter de melhor". (CARVALHO, 19[--]. p. 3-4)

De acordo com a conservadora de museus, as opiniões dos profissionais de museus sobre a aplicação concreta do método do Duplo-Museu dividiam-se em dois conjuntos: a) dos técnicos de museus, que defendiam a retirada de acervos secundários das salas expositivas para os depósitos da instituição, ou mesmo por transferência para museus de província; b) dos arquitetos, que apresentavam como solução a construção de edifícios apropriados às necessidades dos museus modernos (CARVALHO, 19[--]).

Percebe-se, pelos debates sobre o Método do Duplo-Museu, que o estímulo visual do visitante ganhava atenção dos profissionais do campo dos museus. Tanto a seleção dos objetos, como a disposição das salas expositivas tornavam-se premissas para a apresentação dos bens culturais. O crítico de arte, educador e conservador de museus autodidata, José Valladares, ao tratar do Método Duplo-Museu, em seu livro Museu para o povo: um estudo sobre museus americanos (1946) utilizou a metáfora do iceberg para ilustrar a situação das instituições: os museus somente expõem a nona parte dos objetos que possuem, as demais peças encontram-se nos store-room, ou como denominamos atualmente, reservas-técnicas. Valladares (1946) também apresenta o Método do 
Duplo-Museu como uma solução para tratar os objetos como fonte material para fins de estudo, exibição e serviço educacional. Em suas palavras, duas perspectivas estavam em evidência: a científica e a humana:

Quando se pensa no modo de tratar o patrimônio de um museu, dois pontos de vista entram em jogo: o ponto de vista puramente científico e o ponto de vista humano. É necessário procurar que não se atropelem, pois isso iria diminuir as possibilidades de serviço educativo.

Segundo Stein, o ponto de vista científico requer:

1 - Que todas as coleções sejam mostradas.

2 - Que estejam arrumadas em ordem.

3 - Que tudo esteja na melhor luz possível.

4 - Proteção contrafogo, temperatura, luz, poeira e vandalismo ou furto.

5 - Reorganização fácil das coleções visando crescimento ordenado.

O ponto de vista humano, por sua vez, pede:

1 - A divisão das coleções em duas partes - uma para o público em geral e outra somente para estudiosos.

2 - Que as coleções de estudo sejam tão compreensivas quanto possível e arrumadas de sorte a facilitar pesquisa se comparações.

3 - Que as galerias públicas satisfaçam as seguintes condições: a) o visitante somente verá um número limitado de objetos; b) todo objeto será exposto em ambiente correlato; c) cada objeto atrairá a atenção do visitante; d) despertará seu interesse; e) ele não se fatigará com a monotonia da arrumação (VALLADARES, 1946, p. 35).

É possível identificar, tanto na análise de Valladares (1946), como na de Lutz ([1932] 2008) e Carvalho (19[--]), que as funções do museu de preservar e investigar associam-se ao ato de promover o patrimônio cultural. A arrumação do museu e de suas exposições, para divulgação dos bens culturais, tornava-se, no Brasil, uma das competências desenvolvidas no Curso de Museus e, consequentemente, uma habilidade aprofundada na disciplina Técnica de Museus.

Gustavo Barroso, ao tratar do tema arrumação em seu livro de formação Introdução à técnica de museus (BARROSO, 1951), aborda o Método Duplo- 
Museu como uma solução utilizada por profissionais europeus e norteamericanos. A arrumação era uma das habilidades do conservador de museus e o Método Duplo-Museu favorecia a concepção de exposições destinadas ao público geral - na qual a escolha dos objetos era um fator determinante, bem como a apresentação destes bens no espaço - e para o público especializado - montagem de exposições que continham objetos qualificados por Gustavo Barroso como medíocres, mas que eram significativos para estudos e pesquisas sobre o passado (Idem, 1951).

A ênfase das habilidades de arrumação estava centrada no público geral, pois o desafio era estimular uma sensação de harmonia nas visitações. Como referido anteriormente, é possível identificar, entre os agentes do campo, que o estudo das estratégias intituladas como técnica de apresentação e/ou arrumação concentravam-se em dois momentos: a seleção do objeto, ou como a conservadora de museus Regina Real (1958, p. 23) se refere, "[...] escolher bem aquilo que merece ser apresentado"; e a valorização do objeto, etapa não menos importante, uma vez que "[...] não basta colocá-lo [o objeto] para ser visto, é preciso valorizá-lo, equilibrá-lo com que o cerca, de forma a agradar a vista, instruindo" (Idem, 1958, p. 26).

Para a profissional, nesse enfoque, as técnicas museográficas tinham evoluído de forma revolucionária. Todos os elementos que compõem uma exposição deveriam ser meticulosamente pensados: vitrines, paredes, manequins, topografia das salas, iluminação, espaços entre portas e janelas e pés direitos, já que, segundo Gustavo Barroso, "[...] procura-se ao mesmo tempo emocioná-lo [o visitante] e educá-lo, de modo que seu passeio através das coleções expostas seja o mais frutuoso possível no sentido moral e intelectual” (BARROSO, 1951, p. 52).

A possibilidade de vincular recursos, que aprimorassem a experiência visual nas exposições, era de grande interesse dos profissionais dos museus. Estava em pauta o aprimoramento das técnicas museográficas de estímulo ao aprendizado visual. A disposição dos objetos poderia causar a fadiga da visão. $\mathrm{O}$ 
excesso, seja pelo amontoamento, ou mesmo como resultado de métodos empregados, destruía, como Gustavo Barroso advertiu, o "valor pedagógico dos objetos" (BARROSO, 1951, p. 32). Para o professor boa parte do público contentava-se em ter uma boa visão do conjunto e em seu livro elencou os princípios indeclináveis para uma boa exposição:
1) Efeito estético dos próprios objetos.
2) Efeito estético de sua colocação.
3) Facilidade de visão e exame pelo público.
4) Boa e clara etiquetagem.
5) Proteção dos objetos contra as intempéries.
6) Defesa dos mesmos contra descuidos de visitantes e roubos.
7) Preferência dos melhoramentos graduais sobre as reformas subversivas (BARROSO, 1951, p. 32; 37).

O discurso acima apresentado no livro Introdução à técnica de museus (BARROSO, 1951) provoca indagações sobre o direcionamento das estratégias de divulgação concebidas pelos profissionais de museus. É possível observar a intenção de favorecer uma relação mais direta com o patrimônio, pela prévia seleção e disposição do acervo na exposição concebendo, por exemplo, conjuntos narrativos. Essas novas propostas estariam voltadas, sobretudo, para o público que categorizavam como curiosos, ou seja, o público considerado médio por não ser pesquisador, mas que tinha um ávido interesse em aprender. O exercício da educação em museus era propiciado por dois fatores centrais: considerar que os objetos tinham um potencial "valor pedagógico" e que existia um público estimulado a aprender.

Através do Método Duplo-Museu, as técnicas de seleção e disposição do acervo, colocadas em prática, exaltariam os discursos a serem propagados institucionalmente. O conceito de estratégia de Michel de Certeau (1998) caberia nesse contexto, uma vez que essa proposta de divulgação do patrimônio estabeleceria uma relação regulada da experiência proporcionada ao público. 
Porém, cabe ressaltar que as estratégias voltadas ao público curioso eram repletas de prejulgamentos. Observa-se que o professor da disciplina Técnica de Museus exalta como os dois primeiros princípios indeclináveis para uma boa exposição o efeito estético dos próprios objetos e o efeito estético de sua colocação. O Método Duplo-Museu motivava a seleção e disposição do acervo pelo crivo do estético e não pelo valor de documento histórico. Aliás, objetos dotados desse valor informacional poderiam ser acondicionados nas reservas técnicas por não terem apelo visual. Havia, nessa concepção, o reforço da sacralização de evidências materiais pelo crivo do belo, único e diferente, bem como a propagação da ideia de que o público curioso precisava ser estimulado pela atração visual.

Se por um lado a aplicação do Método Duplo-Museu exaltava o apelo estético do objeto, por outro valorizava uma atenção profissional na organização das exposições a fim de evitar o excesso informacional. Diminuir a concentração de acervo exposto ampliava a concentração do visitante e tornava mais nítida a proposta educativa da instituição. Na publicação Museu e educação do conservador de museu Florisvaldo dos Santos Trigueiros (1958) - voltada para os profissionais do campo dos museus, mas também, do campo da educação -, percebe-se um cuidado em condensar, simplificar e exemplificar as técnicas que, no caso do livro Introdução à técnica de museus (BARROSO, 1951), eram formuladas com um vocabulário controlado e especializado:

A arrumação de um museu requer gosto especial e deve ser feita de modo a valorizar as peças expostas, atraindo a curiosidade do visitante. [...] O ambiente é um dos mais importantes problemas do museu e, quando bem resolvido, resulta em vantagens apreciáveis. Deve ser simples e atraente. A pintura das paredes pode variar desde os tons neutros até as cores vivas, uma vez que harmonize com o tipo do museu e com as peças a serem apresentadas. Num museu para crianças, as cores vivas pelo seu poder de atração, podem ser utilizadas. A iluminação, sempre que possível, deve ser a natural; quando esta for insuficiente, ou para realçar certas peças, utiliza-se a luz elétrica, de preferência com lâmpadas fluorescentes. [...]. Também contribui para maior beleza e facilidade de aprendizagem dos que visitarem a exposição, a colocação de retratos de personagens ligados direta ou indiretamente às peças mostradas, como selos, mapas, etc. 
(TRIGUEIROS, 1958, p. 69-71).

A fim de estimular uma educação visual nos museus, métodos complementares e encorpados ao Método Duplo-Museu passaram a ser debatidos e aprimorados nas instituições. O recurso da palavra passou a ser mais explorado para contextualização dos objetos. As etiquetas e os impressos de apoio - catálogos, folhetos, guias de visitantes - passaram a ser produzidos como recursos de apoio a visitação, pois facilitariam o exame do público. De acordo com Ceravollo e Santos (2007) José Valladares, pela experiência acumulada, destacava em suas publicações a importância da palavra aplicada nas exposições de forma a valorizar os objetos. Em reportagem ao jornal soteropolitano A Tarde, de 15 de setembro de 1946, salientou:

Há muita gente que olha com certo desdém para esse cuidado na
exibição das coleções. Os objetos falam por si mesmo - é o que se ouve
com frequência. Mas não pode haver engano mais prejudicial para o
comum dos visitantes. A não ser para especialistas, os objetos nunca
falam satisfatoriamente. Faz-se mister que alguém se encarregue de
falar por eles e essa tarefa compreende desde o modo que a peça está
exibida até a informação contida nas etiquetas, nos catálogos... até a
palavra do guia afável que disserta sobre a significação do conteúdo das
galerias (VALLADARES, 1946 apud CERAVOLO; SANTOS, 2007, p.
209-210).

Para além do recurso textual Bertha Lutz ([1932] 2008) denominou os recursos visuais e sonoros de métodos dinâmicos, pois exploram o som e o movimento, tornando-se elementos muito atraentes nos museus que os empregam. Um dos recursos mais discutidos nas observações e em eventos do campo dos museus era a utilização de fitas cinematográficas nas salas de exposição.

A utilização de métodos dinâmicos nas exposições, em especial o cinema, aparece com destaque na monografia A extensão cultural nos museus (1946) do educador Edgar Süssekind de Mendonça. A partir das experiências observadas, 
Mendonça (1946) sugere o que denominou provisoriamente de museu animado, ou seja, método em que a exposição fornecerá, pelos objetos, o tema central e, em torno da técnica cinematográfica, temas variados seriam contextualizados e desdobrados. Os filmes, de poucos minutos, contribuiriam na "interpretação pedagógica" dos visitantes.

Um estudo realizado por Misan (2008) reitera a circulação dos agentes da educação no campo dos museus, como Edgar Süssekind de Mendonça, na busca de aprimorar recursos que estimulassem o aprendizado pela educação visual - reforçando os preceitos da Escola Ativa. A autora identificou que outros educadores como Fernando de Azevedo, Everardo Backheuser, Francisco Venancio Filho e Jonathas Serrano tiveram interesse entre as décadas de 1930 a 1950 em estudar e publicar sobre museus, cinema e rádio educativo, por exemplo. Interessante observar que, embora compactuassem que os museus são instituições de rotinas seculares, no que tange à educação, problematizavam esses espaços de aprendizado como contributos para o movimento de renovação do ensino.

Um exemplo da aproximação dos educadores com o campo dos museus pode ser evidenciado por meio das contribuições de Venancio Filho. Bemvenuti (2004) destaca que, nas palavras do educador, os museus, para alcançarem o público, deveriam ser espaços amáveis, vivos, alegres e variados, sem monotonia, ao contrário, deveriam converter-se ao mais dinâmico possível. Para alcançarem essa dimensão ativa e, consequentemente, exercer sua função educativa, Venancio Filho apresentou seis estratégias que aprimorariam a educação em museus:

$\left.1^{0}\right)$ Percurso o mais econômico, de forma que seja possível ver-se tudo o que há sem fazer duas vezes o mesmo caminho.

$2^{\circ}$ ) Plantas iniciais, acompanhadas de gráficos e esquemas claríssimos e estéticos, despertando a curiosidade e convidando à visita.

$3^{\circ}$ ) Roteiros bem visíveis e expressivos.

$4^{\circ}$ ) Arrumação ampla, sem amontoados, com circulação fácil e livre, 


\begin{abstract}
lógica e exata.
$5^{\circ}$ ) Catálogos bem feitos, em linguagem simples e nítida, ao alcance de qualquer entendimento.

$\left.6^{\circ}\right)$ Uso de todos os recursos modernos de visualidade e até auditividade: cartogramas, coloridos ou luminosos, estereogramas, mapas de todas as espécies, projeção fixa e animada e especialmente aos fenômenos representados em movimento, seja luminoso, seja mecânico, acionado pelo simples contato de botão elétrico, pela mão do observador (VENANCIO FILHO, 1939 apud BEMVENUTI, 2004, p. 105).
\end{abstract}

É possível que Venancio Filho tenha desenvolvido essa lista a partir das experiências que teve nos museus estrangeiros, exaltados em detalhes em um de seus livros intitulado A Educação e seu aparelhamento moderno (1941). Dedicado a apresentar tendências modernas de promover uma educação orgânica, destaca os museus como possibilidade de uma educação informal, presente em toda parte e capaz de estimular a formação da personalidade do indivíduo.

Ainda que algumas estratégias concebidas pelo campo dos museus sejam hoje revisadas criticamente, ressalta-se que as soluções teórico-metodológicas voltadas para a educação em museus tiveram grande importância por constituírem um conhecimento próprio do campo, fundamentado tanto em aspectos científicos, como na experiência empírica. Entre as soluções debatidas, uma das menções mais recorrentes, na produção brasileira nas décadas em estudo, foi o Método Duplo-Museu. Fomentar a educação em museus, por meio da educação visual, era uma proposta em exploração. Diferentes profissionais interessados em um determinado projeto de nação chegaram à conclusão de que a contemporaneidade exigia um homem consciente, com ideais e senso crítico. Havia a necessidade do aprimoramento de medidas de democratização do ensino brasileiro e os museus seriam instrumentos desse processo. 


\section{CONSIDERAÇÕES FINAIS}

Pensar a História da Educação por meio da História dos Museus é um caminho de pesquisa fértil ainda pouco explorado. De acordo com Faria e Quadrado (2019) há múltiplas possibilidades de investigação, que vão da compreensão das dinâmicas institucionais ao aprofundamento do itinerário de profissionais que atuaram no campo dos museus com esse enfoque. Já Possamai (2012) sugere uma reflexão do conceito de patrimônio como uma categoria de pensamento para as investigações em História da Educação. Cabe reforçar que a História da Educação é capaz de abranger estudos que vão do ensino institucionalizado aos processos de aprendizagem e socialização, tornando-se um campo de múltiplas pesquisas (STEPHANOU; BASTOS, 2005).

O desenvolvimento de uma operação teórico-metodológica sobre a educação em museus estimulou profissionais que atuavam, ou não, nas instituições, e que tinham interesse pelo tema, a se debruçarem no que há de mais singular nesses espaços: o objeto. Para além da salvaguarda do patrimônio, o desafio era apresentá-lo como uma referência cultural. Entre as soluções debatidas, uma das menções mais recorrentes na produção brasileira nas décadas em estudo foi o Método Duplo-Museu. Essa era uma estratégia sugerida para concentrar o impacto visual sobre o visível e direcionar uma narrativa preestabelecida para o público.

A partir dos debates sobre educação no campo dos museus identifica-se uma atenção mais reflexiva sobre o processo técnico efetuado nessas instituições, pois há uma percepção de que é por meio da cadeia operatória básica que os museus interagem com a sociedade. Problematizar o uso social do patrimônio cultural preservado nos museus passa a ser uma discussão em ascendência no campo.

Se atualmente tem-se o entendimento de que a existência dessas instituições se centra na participação e envolvimento do público, crédito deve ser conferido às estratégias que visavam romper com uma função de museu limitada 
às práticas de preservação do acervo museológico. A crescente valorização da função educativa dos museus motivou agentes a (re) pensarem o papel do museu no mundo contemporâneo e, gradativamente, a cada ruptura, legitimá-lo como espaço de aprendizado. Nesse sentido, a valorização gradual do público e o amplo acesso ao patrimônio, pelas propostas de educação visual e educação para o "povo", suscitaram necessidades complexas que impulsionaram a fundamentação do conhecimento adquirido pelo estudo e prática da Museologia, defendida a partir da segunda metade do século XX como uma ciência.

\section{REFERÊNCIAS}

BARBOSA, Ana Mae. Redesenhando o desenho: educadores, política e história. São Paulo: Cortez, 2015. 456 p.

BARROS, Sigrid Pôrto. A mensagem cultural do Museu. Anais do Museu Histórico Nacional, v. XIII. Rio de Janeiro: Ministério da Educação e Cultura, 1964. p.216-228. [Volume atribuído ao ano 1952].

BARROSO, Gustavo. Introdução à técnica de museus. v. 1, 2. ed. Rio de Janeiro: Ministério da Educação e Saúde/ Gráfica Olímpica, 1951. 350 p.

BEMVENUTI, Alice. Museus e educação em museus - história, metodologias e projetos, com análises de caso: Museus de Arte Contemporânea de São Paulo, Niterói e Rio Grande do Sul, 2004. 380 f. Dissertação (Mestrado em Artes Visuais) - Programa de Pós-Graduação em Artes Visuais, Universidade Federal do Rio Grande do Sul, Rio Grande do Sul, 2004. Disponível em:

https://www.lume.ufrgs.br/bitstream/handle/10183/49164/o00835365.pdf?se quence=1. Acesso em: 6 dez. 2019.

BERTHELOT, Pierre; HILAIRE, Georges; BRUNON-GUARDIA, Georges (org.). Les cahiers de la république des léttres des sciences et des arts: musées, Paris, n. 13, 1931.

CARVALHO, Nair de Moraes. Cópia, Rio de Janeiro, 1946. [Projeto de Memória da Museologia no Brasil do Curso de Museologia da Universidade Federal do Estado do Rio de Janeiro, Coleção Nair de Moraes Carvalho (NMC)/Série Museologia I (1937-1946)/Caixa 09, NMC2218]. 
CARVALHO, Nair de Moraes. O Método do Duplo-Museu. 19[--], 5 fls.

CERAVOLO, Suely Moraes. Uma análise sobre museus na década de 1940: o estudo de José Antonio do Prado Valladares. História, Ciências, Saúde Manguinhos, v. 19, n. 2, p. 769-773, 2012. Disponível em: http://www.scielo.br/scielo.php?script=sci_arttext\&pid=So10459702012000200027. Acesso em: 16 nov. 2019.

CERAVOLO, Suely Moraes; SANTOS, Daisy Conceição dos. Apontamentos sobre José Antonio do Prado Valladares - "um homem de museu”. Cadernos do CEOM, ano 20, n. 26, p. 195-221, 2007. Disponível em: https://bell.unochapeco.edu.br/revistas/index.php/rcc/article/view/2025. Acesso em: 6 dez. 2019.

CERTEAU, Michel de. A invenção do cotidiano: $1^{0}$. Artes de fazer. Tradução: Ephraim Ferreira Alves. 3. ed. Rio de Janeiro: Editora Vozes, 1998.

CHAGAS, Mário de Souza; RODRIGUES, Marcus Vinícius Macri (org.). A função educacional dos museus: 60 anos do Seminário Regional da Unesco. Rio de Janeiro: Museu da República, 2019. Disponível em: http://museudarepublica.museus.gov.br/wpcontent/uploads/2019/05/Livro_seminario_WEB.pdf. Acesso em: 29 fev. 2020.

CRUZ, Henrique de Vasconcelos. Era uma vez, há 60 anos atrás...: o Brasil e a criação do Conselho Internacional de Museus. ICOM-BR, 2008. 15p.

FARIA, Ana Carolina Gelmini de. Educar no museu: o Museu Histórico Nacional e a educação no campo dos museus (1932-1958), 2017, 296 f. Tese (Doutorado em Educação) - Programa de Pós-Graduação em Educação, Universidade Federal do Rio Grande do Sul, Porto Alegre, 2017. Disponível em: https://lume.ufrgs.br/handle/10183/158339. Acesso em: 29 fev. 2020.

FARIA, Ana Carolina Gelmini de; QUADRADO, Iandora de Melo. Estudar os museus e patrimônios na perspectiva da História da Educação: caminhos possíveis. Sillogés, v. 2, n. 1, p. 132-151, 2019. Disponível em: http://historiasocialecomparada.org/revistas/index.php/silloges/article/view/3 9/59. Acesso em: 6 dez. de 2019.

GIL, Carmem Zeli de Vargas; POSSAMAI, Zita Rosane. Educação patrimonial: percursos, concepções e apropriações. Mouseion, n. 19, 2014. Disponível em: https://revistas.unilasalle.edu.br/index.php/Mouseion/article/view/1874/1232 . Acesso em: 29 fev. 2020. 
HOLLANDA, Guy de. Recursos educativos dos museus brasileiros. Rio de Janeiro: CBPE-Onicom, 1958. 268p.

KNAUSS, Paulo. A presença de estudantes e o encontro de museus e escola no Brasil a partir da década de 50 do século XX. Revista Varia História, Belo Horizonte, v. 27, n. 46., p. 581-597, 2011. Disponível em:

http://www.scielo.br/scielo.php?pid=So10487752011000200010\&script=sci_abstract\&tlng=pt. Acesso em: 6 dez. 2019.

LUDOLF, Dulce Cardozo. Nova Diretriz para o Museu. Anais do Museu Histórico Nacional, v. XIII. Rio de Janeiro: Ministério da Educação e Cultura, 1964. p. 189-200. [Volume atribuído ao ano 1952].

LUTZ, Bertha Maria Julia. A função educativa dos museus, 1932. Adaptação de Guilherme Gantois de Miranda; Maria José Veloso da Costa Santos; Silvia Ninita de Moura Estevão e Vitor Manoel Marques da Fonseca. Rio de Janeiro: Museu Nacional; Niterói: Muiraquitã, 2008. 240 p.

MAURÍCIO, Jayme. "Ver" ainda é a mais larga avenida do saber. Itinerário das Artes Plásticas. Correio da Manhã, Rio de Janeiro, 6 de outubro de 1956.

MENDES, Alessandro Araújo. O movimento da Escola Nova e a educação do povo e dos filhos da elite brasileira. $9^{\circ}$ Encontro Internacional de Formação de Professores e $10^{\circ}$ Fórum Permanente de Inovação Educacional, Aracajú, v. 8, n. 1, 2015.11 p.

MENDONÇA, Edgar Süssekind de. A extensão cultural nos museus. Rio de Janeiro: Imprensa Nacional, 1946. 72 p. (Série Museu Nacional publicações avulsas; n. 2). Disponível em:

http://flanelografo.com.br/impermanencia/biblioteca/Mendonca\%20(1946).pd f. Acesso em: 16 nov. 2019.

MISAN, Simona. Os museus históricos e pedagógicos do estado de São Paulo. Anais do Museu Paulista, São Paulo. n. sér. v. 16. n. 2, 2008. p. 175-204. Disponível em: http://www.scielo.br/scielo.php?script=sci_arttext\&pid=So10147142008000200006. Acesso em: 6 dez. 2019.

OFFICE INTERNATIONAL DES MUSÉES. Muséographie. v. 2. Paris: Société des nations, Office international des musées, Institut international de coopération intellectuelle, $1935.231 \mathrm{p}$.

PESAVENTO, Sandra Jatahy. O mundo da imagem: território da história cultural. In: PESAVENTO, Sandra Jatahy; SANTOS, Nádia Maria Weber; ROSSINI, Miriam de Souza (org.). Narrativas, imagens e práticas sociais: 
percursos em história cultural. Porto Alegre: Asterisco, 2008. p. 99-122.

POSSAMAI, Zita Rosane. Patrimônio e História da Educação: aproximações e possibilidades de pesquisa. Revista História da Educação, v. 16, n. 36, p. 110-120, 2012. Disponível em: https://seer.ufrgs.br/asphe/article/view/19976. Acesso em: 6 dez. 2019.

REAL, Regina Monteiro. Museu ideal. Belo Horizonte: Tipografia da Faculdade de Direito da Universidade de Minas Gerais e do Centro Regional de Pesquisas Educacionais, 1958. 40 p.

RIBEIRO, Henrique de Vasconcelos Cruz. Um capítulo na história da museologia no Brasil: um olhar sobre o surgimento do Curso de Museus do Museu Histórico Nacional (1922-1935), 2014. 116 p. Dissertação (Mestrado em Museologia e Patrimônio) - Programa de Pós-Graduação em Museologia e Patrimônio do Centro de Ciências Humanas e Sociais, Universidade Federal do Estado do Rio de Janeiro /Unirio, Museu de Astronomia e Ciências Afins/MAST, Rio de Janeiro, 2014. Disponível em: http://www.unirio.br/ppgpmus/front-page. Acesso em: 16 nov. 2019.

RIVIÈRE, Georges Henri. Tradução: Maria Cistina Oliveira Bruno e Maria Pierina Ferreira de Camargo. Documento final do Seminário Regional da Unesco sobre a Função Educativa dos Museus. Rio de Janeiro: ICOM/Unesco, 1958. In: ARAÚJO, Marcelo Mattos; BRUNO, Maria Cristina Oliveira (org.). A memória do pensamento museológico contemporâneo. São Paulo: Comitê Brasileiro do ICOM, 1995. p.11-16.

STEPHANOU, Maria; BASTOS, Maria Helena Camara. História, memória e história da educação. In: STEPHANOU, Maria; BASTOS, Maria Helena Camara (org.). Histórias e memórias da educação no Brasil, v. III - século XX. Petrópolis: Vozes, 2005. p. 416-429.

TORAL, Hernan Crespo. Tradução: Marcelo Mattos Araújo. Seminário Regional da Unesco sobre a Função Educativa dos Museus - 1958. Havana, 1995. In: ARAÚJO, Marcelo Mattos; BRUNO, Maria Cristina Oliveira (org.). A memória do pensamento museológico contemporâneo. São Paulo: Comitê Brasileiro do ICOM, 1995. p.8-10.

TRIGUEIROS, Florisvaldo dos Santos. Museu e educação. Rio de Janeiro: Irmãos Pongetti, 1958. 228p.

VALLADARES, José Antonio do Prado. Museus para o povo: um estudo sobre museus americanos. 1. ed., n. 6. Bahia: Publicações do Museu do Estado da Bahia/Minsitério da Educação e Saúde, 1946. 105 p. 
VELLOSO, Mônica Pimenta. Os intelectuais e a política cultural do

Estado Novo. Rio de Janeiro: Centro de Pesquisa e Documentação de História Contemporânea do Brasil, 1987.50 p.

\section{VENANCIO FILHO, Francisco. A educação e seu aparelhamento}

moderno. Série 3, v. 38. São Paulo, Rio, Recife, Porto Alegre: Companhia Editora Nacional, 1941. 222 p. [Coleção Biblioteca Pedagógica Brasileira].

ANA CAROLINA GELMINI DE FARIA é museóloga formada pela Universidade Federal do Estado do Rio de Janeiro (Unirio), com especialização em Psicopedagogia Institucional e Educação Especial pela Universidade Veiga de Almeida (UVA). Mestre e doutora em Educação pela Universidade Federal do Rio Grande do Sul (UFRGS). Atualmente é professora adjunta do Curso de Bacharelado em Museologia do Departamento de Ciências da Informação da Universidade Federal do Rio Grande do Sul (DCl/Fabico/ UFRGS) e professora do Programa de Pós-Graduação em Museologia e Patrimônio da mesma Universidade (PPGMUSPA/UFRGS).

E-mail: carolina.gelimini@ufrgs.br

(iD) http://orcid.org/0000-0003-0727-9991

Recebido em: 26 de dezembro de 2019

Aprovado em: 06 de junho de 2020

Revista História da Educação - RHE

Associação Sul-Rio-Grandense de Pesquisadores em História da Educação - Asphe

Artigo de acesso aberto distribuído nos termos de licença Creative Commons. 